EDITOR'S

\title{
Is youth smoking responsive to cigarette prices? Evidence from low- and middle-income countries
}

\author{
Deliana Kostova, ${ }^{1}$ Hana Ross, ${ }^{2}$ Evan Blecher, ${ }^{2}$ Sara Markowitz ${ }^{1}$
}

'Department of Economics, Emory University, Atlanta, Georgia, USA

${ }^{2}$ American Cancer Society, Atlanta, Georgia, USA

Correspondence to Deliana Kostova, Emory University, Department of Economics, 1602 Fishburne Drive, Atlanta, Georgia 30322, USA; dkostov@emory.edu

Received 7 July 2010 Accepted 9 June 2011 Published Online First 7 July 2011

\begin{abstract}
Objective To estimate the price elasticity of cigarette demand among youth in low- and middle-income countries (LMIC).

Data The Global Youth Tobacco Survey was used to obtain data on the smoking behaviour of 315353 adolescents from 17 LMIC.

Design Two-part model of cigarette demand with country fixed effects. The first part estimates the impact of prices on smoking participation while the second part estimates the impact of prices on the number of cigarettes smoked among current smokers. Besides controlling for individual characteristics such as Age, Gender, Parental Smoking and availability of Pocket Money, the authors control for confounding environmental factors such as anti-smoking sentiment, the prevalence of cigarette advertising and anti-tobacco media messAges, and ease of purchasing cigarettes. All countries in this study are represented with at least two observations over time, which allows us to control for unobserved country characteristics and/or policies that may influence smoking patterns within countries.
\end{abstract}

Results Cigarette price is an important determinant of smoking. The estimated price elasticity of smoking participation is -0.74 , and the estimated price elasticity of conditional cigarette demand is approximately -1.37 . The total price elasticity of cigarette demand is -2.11 , implying that an increase in price of $10 \%$ would reduce youth cigarette consumption by $21.1 \%$ at the mean.

\section{INTRODUCTION}

Tobacco consumption is a leading cause of preventable death, with 100 million deaths attributed to it during the 20th century and nearly one billion deaths projected during the 21 st century. ${ }^{1}$ Low- and middle-income countries (LMIC) are likely to carry a disproportionate part of the world's tobacco-associated health burden due to a combination of growing tobacco consumption and substandard healthcare. Tobacco use in LMIC is on the rise and can begin very early in life. It is estimated that, worldwide, one in seven teenAgers smokes, and a quarter of them have tried their first cigarette before the Age of $10 .^{2}$ Prevention of tobacco use among adolescents is particularly important for tobacco control because smoking habits are established primarily in youth.

Although youth tobacco use is a global problem, virtually all evidence on the economic determinants of youth smoking comes from high-income countries (HIC) and primarily from US data. US estimates of the total price elasticity of cigarette demand for youth range from $-1.44,{ }^{3}-1.31,{ }^{4}$ $-1.11,{ }^{5}-0.83,{ }^{6}-0.7^{78}$ to statistically zero. ${ }^{9}$ To the best of our knowledge, no prior studies provide estimates of cigarette price elasticities among youth in LMIC although there is limited evidence on adults from some LMIC. ${ }^{10} 11$ Lance et al (2004) estimate the effect of price on adult male smoking in China and Russia and find very weak price responsiveness. Chapman and Richardson (1990) rely on aggregate country data, which raises concerns about the ability to identify a causal price effect in a model where cigarette prices and cigarette demand are simultaneously determined.

A common concern with evaluating the impact of price in studies that pool data from different geographical locations is confounding bias from unobserved country or state characteristics. An example of an unobserved country-specific confounder is anti-smoking sentiment. For instance, countries with higher prevalence of anti-smoking sentiment are likely to have lower cigarette consumption, and, at the same time, they may be more likely to pass heavier cigarette taxation and to have higher prices. In such case, unless anti-smoking sentiment is controlled for, we cannot be certain that the observed negative correlation between cigarette prices and cigarette consumption represents a true price effect as it may merely be a reflection of the local attitudes towards smoking. Recent US studies that control for differences in anti-smoking sentiment across US states disagree regarding the importance of cigarette price as a determinant of youth smoking. ${ }^{9} 1213$ This mixed evidence hinders the extrapolation of US-based results to other countries. Even if uniform evidence on US price effects had been available, US results cannot be easily generalised to other countries due to a variety of differences among the populations.

Our study addresses the current need for evidence regarding the impact of prices on youth cigarette consumption in LMIC and provides estimates of the price elasticity of cigarette demand. Bias from country-specific unobservable factors is reduced by including (1) country fixed effects that control for unobserved time-invariant country characteristics and (2) a proxy for local antismoking sentiment. We further reduce estimation bias by controlling for confounding environmental factors such as rates of exposure to cigarette advertising and anti-tobacco media messAges, and ease of purchasing cigarettes.

\section{DATA AND METHODS}

The Global Youth Tobacco Survey (GYTS) provides individual-level data on youth smoking behaviour, their personal characteristics and environments. GYTS is a school-based survey developed by the WHO and Centers for Disease Control and Prevention (CDC) to track tobacco use among 
young people across countries with a common methodology. It has been conducted in 135 LMIC from the six WHO world regions (Africa, Europe, Pan-American, Southeast Asia, Middle East and Western Pacific) in various years since 1999. It captures prevalence, access, media exposure and attitudes related to tobacco use among individuals in school grades corresponding to Ages 13-15, although in practice the Age range of the survey is wider and covers individuals between the Ages of 11 and 19 with an averAge Age of 14 years. The survey is designed to be a random sample of schoolchildren, and a major limitation is that it does not capture children who are not enrolled in school.

We constructed our final dataset by merging individual-level data from GYTS with country-level data on local cigarette prices obtained from the Economist Intelligence Unit's (EIU) World Cost of Living Survey. The final dataset has observations on 315353 individuals from 17 countries corresponding to 113 local sites (ie, cities/provinces). The number of countries used in this study is smaller than the total number of GYTS countries for the following reasons. First, we excluded countries for which cigarette price data were unavailable (82 countries excluded). Second, we kept only countries that were surveyed in multiple years, allowing the use of country fixed effects (33 countries excluded). Finally, we excluded three more countries due to their classification as HIC (Kuwait, United Arab Emirates and Poland). Descriptive statistics of the sample and variables used in this study are shown in table 1 . Sample means with countrylevel detail are shown in table 2 .

Smoking participation is captured by a binary variable equal to 1 if an individual smoked at least one cigarette in the past month and 0 otherwise. The highest smoking prevalence in our sample is observed in Russia (23\%) and Chile (24\%). Smoking intensity among smokers is calculated by multiplying the averAge number of smoking days by the averAge number of cigarettes smoked per day in the past month, both of which are obtained from GYTS responses. In this sample, the averAge cigarette consumption ranges from 1.5 to 630 cigarettes per month. On averAge, the highest consumption is concentrated among a minority of individuals, and more than half of our LMIC youth sample smokes less than a pack per month (table 3). Individual control variables include Age, Gender, Parental Smoking status and availability of Pocket Money. The latter is captured by a binary indicator equal to 1 if the subject receives Pocket Money/personal income and serves as a proxy for personal and family income that is not otherwise available in GYTS. Education is not included since the level of education across survey participants is fairly constant and represents middle-school grades only.

Cigarette prices are obtained from the EIU World Cost of Living Survey, which collects retail price data for a wide range of consumer products from multiple cities worldwide. ${ }^{14}$ Cigarette prices are available for two different brands, a local brand and a foreign brand (usually Marlboro) collected from one or more cities in each country. If cigarette prices come from multiple cities in one country, we use the averAge national price. Where the GYTS city survey site matches the EIU city survey site, local city prices are used instead of the nationally averAged price. Prices are expressed in real 2000 US dollars and are adjusted using purchasing power parity conversion factors obtained from the World Bank's World Development Indicators database. ${ }^{15}$ Purchasing power parity adjusts prices for the local standard of living and allows for more accurate price comparison between countries. Prices are log-transformed so that we can directly estimate the impact of a per cent change in price.

The environment of each subject is captured by the level of anti-smoking sentiment (Sentiment), the local prevalence of cigarette advertising (Cigarette Advertising), the local prevalence of anti-tobacco media messAges (Anti-Tobacco Media) and a general measure of the ease of purchasing cigarettes (Youth Access). All of these are constructed by aggregating individual survey responses at the site level.

Sentiment is defined as the percentAge of non-smokers in each survey site who favour bans on smoking in public places. Antismoking sentiment has been recognised as an important factor for smoking behaviour. ${ }^{9} 16$ We exclude smokers from the construction of anti-smoking sentiment because smokers are disproportionately more likely than non-smokers to disapprove of smoking bans and would inflate the relationship between sentiment and smoking by virtue of their weight alone. ${ }^{9}{ }^{13}$ If Sentiment included smokers, Sentiment would appear to have a larger impact on smoking because it would be difficult to disentangle what part of the impact is driven by true differences in sentiment across sites and what part is driven merely by

Table 1 Sample means and variable definitions

\begin{tabular}{|c|c|c|c|c|c|c|c|c|}
\hline \multirow[b]{2}{*}{ Variable type } & \multirow[b]{2}{*}{ Variable name } & \multirow[b]{2}{*}{ Variable description } & \multicolumn{3}{|c|}{$\begin{array}{l}\text { Full sample } \\
(\mathrm{n}=\mathbf{3 1 5} 353)\end{array}$} & \multicolumn{3}{|c|}{$\begin{array}{l}\text { Smokers only } \\
(\mathrm{n}=29782)\end{array}$} \\
\hline & & & Mean & Min & $\overline{\operatorname{Max}}$ & Mean & Min & $\overline{\operatorname{Max}}$ \\
\hline \multirow[t]{6}{*}{ Individual level } & Current smoker & 1 if smoked at least one cigarette in past month, 0 otherwise & 0.09 & 0 & 1 & 1 & 1 & 1 \\
\hline & Cigarette demand & Number of cigarettes smoked in past month & 6.3 & 0 & 630 & 66.5 & 1.5 & 630 \\
\hline & Age & Age in years & 14.0 & 8.7 & 19.4 & 14.5 & 10.1 & 19.0 \\
\hline & Male & 1 if male, 0 otherwise & 0.50 & 0 & 1 & 0.63 & 0 & 1 \\
\hline & Pocket money & 1 if receives pocket money/income, 0 otherwise & 0.61 & 0 & 1 & 0.84 & 0 & 1 \\
\hline & Parental smoking & 1 if at least one parent smokes, 0 otherwise & 0.47 & 0 & 1 & 0.64 & 0 & 1 \\
\hline \multirow[t]{4}{*}{ Site level } & Anti-smoking sentiment & Proportion of non-smokers who support bans on public smoking & 0.83 & 0.40 & 0.96 & & & \\
\hline & Cig. advertising exposure & $\begin{array}{l}\text { Proportion of survey respondents who report recent exposure to cigarette } \\
\text { advertising in print media }\end{array}$ & 0.87 & 0.44 & 0.99 & & & \\
\hline & $\begin{array}{l}\text { Anti-tobacco media } \\
\text { exposure }\end{array}$ & $\begin{array}{l}\text { Proportion of survey respondents who report recent exposure to anti-smoking } \\
\text { media messages }\end{array}$ & 0.83 & 0.61 & 1.00 & & & \\
\hline & Youth access & $\begin{array}{l}\text { Proportion of survey respondents who report being unable to buy cigarettes } \\
\text { due to age }\end{array}$ & 0.36 & 0.05 & 0.87 & & & \\
\hline \multirow[t]{2}{*}{ Country level } & Price, local brand & Real price of local-brand cigarettes, PPP-adjusted, constant year 2000 USD & 2.44 & 1.08 & 5.16 & & & \\
\hline & Price, foreign brand & Real price of foreign-brand cigarettes, PPP-adjusted, constant year 2000 USD & 3.32 & 1.45 & 8.94 & & & \\
\hline
\end{tabular}

PPP, purchasing power parity. 
Table 2 Sample means by country and region

\begin{tabular}{|c|c|c|c|c|c|c|c|c|c|c|c|c|}
\hline Region* & Country & Years & $\begin{array}{l}\text { Smoking } \\
\text { preval- } \\
\text { ence } †\end{array}$ & $\begin{array}{l}\text { Cond. } \\
\text { cig. } \\
\text { demand } \neq\end{array}$ & $\begin{array}{l}\text { Pocket } \\
\text { money } \S\end{array}$ & $\begin{array}{l}\text { Parental } \\
\text { smoking }\end{array}$ & $\begin{array}{l}\text { Anti- } \\
\text { smoking } \\
\text { sentiment** }\end{array}$ & $\begin{array}{l}\text { Cig. } \\
\text { adver- } \\
\text { tising } \dagger \dagger\end{array}$ & $\begin{array}{l}\text { Anti- } \\
\text { tobacco } \\
\text { media } \neq \neq\end{array}$ & $\begin{array}{l}\text { Youth } \\
\text { access } \S \S\end{array}$ & $\begin{array}{l}\text { Cig. price, } \\
\text { local } \\
\text { brand } \Phi \uparrow\end{array}$ & $\begin{array}{l}\text { Cig. price, } \\
\text { foreign } \\
\text { brand }^{* * *}\end{array}$ \\
\hline Africa & $\begin{array}{l}\text { South } \\
\text { Africa }\end{array}$ & 1999, 2002 & $17.3 \%$ & 96.9 & 0.43 & 0.45 & 0.58 & 0.84 & 0.78 & 0.35 & 2.97 & 3.02 \\
\hline \multirow[t]{4}{*}{ Mideast } & Egypt & 2001, 2005 & $3.3 \%$ & 72.7 & 0.64 & 0.52 & 0.87 & 0.75 & 0.76 & 0.44 & 3.46 & 3.53 \\
\hline & Jordan & 1999, 2003 & $12.2 \%$ & 90.0 & 0.70 & 0.52 & 0.80 & 0.79 & 0.73 & 0.33 & 1.57 & 3.58 \\
\hline & Morocco & 2001, 2006 & $3.7 \%$ & 96.1 & 0.40 & 0.27 & 0.81 & 0.69 & 0.70 & 0.43 & 2.68 & 5.26 \\
\hline & Pakistan & 2003, 2004 & $1.0 \%$ & 82.7 & 0.67 & 0.32 & 0.96 & 0.81 & 0.78 & 0.58 & 2.23 & 3.60 \\
\hline Mideast average & & & $5.4 \%$ & 87.8 & 0.62 & 0.42 & 0.87 & 0.77 & 0.75 & 0.46 & 2.48 & 3.81 \\
\hline Europe & Russia & 2002,2004 & $22.8 \%$ & 123.3 & 0.79 & 0.63 & 0.91 & 0.81 & 0.87 & 0.47 & 1.95 & 3.74 \\
\hline \multirow[t]{6}{*}{ Americas } & Brazil & $\begin{array}{l}2002,2004,2005 \\
2006\end{array}$ & $9.8 \%$ & 89.4 & 0.58 & 0.37 & 0.89 & 0.87 & 0.88 & 0.19 & 1.60 & 1.78 \\
\hline & Chile & 2000, 2003 & $23.6 \%$ & 45.2 & 0.75 & 0.63 & 0.88 & 0.89 & 0.80 & 0.17 & 2.98 & 3.62 \\
\hline & Costa Rica & 1999, 2002 & $14.6 \%$ & 56.0 & 0.66 & 0.31 & 0.90 & 0.95 & 0.81 & 0.35 & 1.39 & 1.73 \\
\hline & Mexico & $2000,2005,2006$ & $12.4 \%$ & 40.9 & 0.64 & 0.40 & 0.89 & 0.91 & 0.85 & 0.49 & 2.01 & 2.59 \\
\hline & Peru & 2000, 2002, 2003 & $11.8 \%$ & 24.5 & 0.63 & 0.41 & 0.91 & 0.88 & 0.90 & 0.28 & 2.76 & 3.32 \\
\hline & Venezuela & 1999, 2001, 2003 & $4.1 \%$ & 36.0 & 0.56 & 0.37 & 0.88 & 0.86 & 0.81 & 0.33 & 2.37 & 2.64 \\
\hline Americas average & & & $11.5 \%$ & 51.3 & 0.62 & 0.41 & 0.89 & 0.88 & 0.85 & 0.31 & 2.15 & 2.56 \\
\hline \multirow[t]{3}{*}{ Southeast Asia } & India & $\begin{array}{l}2000,2001,2002 \\
2003,2004,2006\end{array}$ & $5.5 \%$ & 59.4 & 0.47 & 0.45 & 0.76 & 0.92 & 0.79 & 0.49 & 3.33 & 4.80 \\
\hline & Indonesia & $\begin{array}{l}2000,2004,2005 \\
2006\end{array}$ & $11.8 \%$ & 35.4 & 0.93 & 0.57 & 0.91 & 0.96 & 0.91 & 0.37 & 1.70 & 2.02 \\
\hline & Sri Lanka & 1999, 2003 & $1.5 \%$ & 34.1 & 0.68 & 0.48 & 0.93 & 0.88 & 0.87 & 0.59 & 4.92 & 7.35 \\
\hline Southeast Asia average & & & $6.2 \%$ & 52.7 & 0.54 & 0.47 & 0.79 & 0.92 & 0.81 & 0.47 & 3.05 & 4.30 \\
\hline \multirow[t]{2}{*}{ Western Pacific } & China & 1999, 2001, 2005 & $4.7 \%$ & 88.8 & 0.75 & 0.64 & 0.62 & 0.66 & 0.78 & 0.16 & 2.40 & 3.43 \\
\hline & $\begin{array}{l}\text { The } \\
\text { Philippines }\end{array}$ & 2000,2004 & $11.9 \%$ & 58.5 & 0.58 & 0.58 & 0.66 & 0.91 & 0.87 & 0.49 & 1.17 & 1.63 \\
\hline Western Pacific average & & & $7.3 \%$ & 71.3 & 0.69 & 0.62 & 0.63 & 0.70 & 0.79 & 0.22 & 1.91 & 2.71 \\
\hline
\end{tabular}

*Regions follow WHO geographical designation.

$\dagger \%$ survey respondents who smoked at least one cigarette in past month.

$\ddagger$ Number of cigarettes smoked in past month.

§Proportion of survey respondents who reported receiving pocket money or income.

\Proportion of survey respondents who have at least one parent who smokes.

**Proportion of non-smokers who support bans on public smoking.

$\dagger †$ Proportion of survey respondents who report recent exposure to cigarette advertising in print media.

$\neq \ddagger$ Proportion of survey respondents who report recent exposure to anti-smoking media messages.

$\S \S$ Proportion of survey respondents who report being unable to buy cigarettes due to age.

ฯฯReal price of local-brand cigarettes, PPP-adjusted, constant 2000 USD.

***Real price of foreign-brand cigarettes, PPP-adjusted, constant 2000 USD.

variability in the proportion of smokers. By contrast, a sentiment variable constructed from the aggregated attitudes of nonsmokers is less likely to contain simultaneity bias when modelled against smoking rates, and its impact on smoking is less likely to be overestimated (this is confirmed by a sensitivity analysis we conducted comparing smokers-inclusive to non-smokers-only Sentiment estimates).

Cigarette Advertising represents the local prevalence of cigarette advertising and is calculated as the proportion of survey participants who have been recently exposed to cigarette ads on billboards, newspapers or magazines. Anti-Tobacco Media represents the local prevalence of anti-tobacco media campaigns and is determined by the proportion of respondents who have recently been exposed to anti-smoking messAges in broadcast

Table 3 Distribution of conditional cigarette demand

\begin{tabular}{lc}
\hline & Number of cigarettes per month \\
\hline Mean & 66.5 \\
Min & 1.5 \\
10th percentile & 1.5 \\
25th percentile & 3.8 \\
Median & 14.0 \\
75th percentile & 84.0 \\
90th percentile & 224.8 \\
Max & 630.0 \\
\hline
\end{tabular}

and print media. Youth Access is calculated as the proportion of survey participants who have recently tried to purchase cigarettes but were turned away by vendors due to their age. Cigarette Advertising, Anti-Tobacco Media and Youth Access are not intended to represent the effects of underlying tobacco-control policies such as tobacco advertising bans or sales bans to minors, although, under certain assumptions, they can be used to provide a glimpse into the potential impact of such policies. Youth Access, in particular, cannot be interpreted as a proxy for sales bans to minors because some countries did not have such bans at the time of the survey (Chile, Indonesia, Morocco, the Philippines) and because some survey participants may be above the legal Age limit in countries where bans were present. Instead, the role of Youth Access is to account for differences across countries in the ease of obtaining cigarettes from points of sale and can reflect the extent to which the habits of young smokers can be enabled by vendors.

We use a two-part model to estimate the impact of price on youth smoking. This model allows for independence between the decision to smoke and the decision of how much to smoke. The first part estimates the probability of smoking participation using a logit model. The second part estimates the amount of cigarettes smoked by smokers with a generalised linear model. We present results from two specifications. The first specification provides a baseline estimate of the price effect without controlling for environmental characteristics. The second 
specification adds controls for Anti-Smoking Sentiment, Cigarette Advertising, Anti-Tobacco Media and Youth Access. Each specification is estimated using both local-brand and foreign-brand cigarette prices. Models using foreign-brand cigarette prices contained one country less than models using local-brand prices because one country (Morocco) did not have data on foreignbrand prices. All specifications control for Age in quadratic form, Gender, Parental Smoking, Pocket Money, and year and country fixed effects.

\section{RESULTS}

\section{Smoking participation}

Results from the smoking participation models are presented in table 4 for local-brand prices and table 5 for foreign-brand prices. A comparison between the baseline and inclusive specifications in tables 4 and 5 shows that accounting for environmental characteristics such as anti-smoking sentiment, media effects and youth access reduces the magnitude of the impact of cigarette price on the probability of smoking but does not reduce its statistical significance. The estimated price elasticity of participation in the baseline specification is -1.01 for local-brand cigarettes and -1.62 for foreign-brand cigarettes. In the inclusive specification, after controlling for environmental factors, elasticity is reduced to -0.74 and -1.09 for local- and foreignbrand cigarettes, respectively. This implies that a $10 \%$ increase in price would correspond to a $7.4 \%$ averAge decline in smoking participation using local-brand prices and $10.9 \%$ decline in participation using foreign-brand prices.

Anti-smoking sentiment is shown to be a significant predictor of participation and has the expected negative sign, confirming that higher anti-smoking sentiment is indeed associated with lower youth smoking prevalence. However, unlike DeCicca et al (2002, 2008), and more in line with Carpenter and Cook (2008), we find that although controlling for Sentiment is necessary for improving the precision of the price estimates, it does not remove the effect of price (tables 4 and 5).

The local prevalence of cigarette advertising is associated with higher youth smoking participation and the local prevalence of anti-tobacco media messAges is found to reduce smoking participation. Using simple linear extrapolation from the localbrand cigarette model in table 4, we estimate that if cigarette advertising was successfull in reaching every single individual (so that the proportion of youth exposed to advertising approached $100 \%$ from the current mean of $87 \%$ ), the averAge smoking

Table 4 Logit models of smoking participation (local-brand cigarettes)

\begin{tabular}{|c|c|c|}
\hline & Baseline $†$ & $\begin{array}{l}\text { Inclusive of environmental } \\
\text { site-specific controls } \dagger \neq\end{array}$ \\
\hline Log price (local brand) & $\begin{array}{l}-0.065^{* * *} \\
(0.019)\end{array}$ & $-0.043^{* * *}(0.015)$ \\
\hline Anti-smoking sentiment & & $-0.094^{* * *}(0.026)$ \\
\hline Cigarette advertising & & $0.126^{* * *}(0.045)$ \\
\hline Anti-tobacco media & & $-0.088 *(0.046)$ \\
\hline Youth access & & $-0.102 * * *(0.028)$ \\
\hline Price elasticity of smoking participation & $-1.101^{* * *}$ & $-0.741^{* * *}$ \\
\hline \multicolumn{3}{|c|}{$\begin{array}{l}\text { Coefficients represent the marginal effect of each variable on the probability (rate) of } \\
\text { smoking participation. } \\
\text { SEs clustered by survey site. } \\
\text { SEs in parentheses. } \\
{ }^{*} p<0.1 ;{ }^{* *} p<0.01 \text {. } \\
\text { †All specifications include Age, Age Squared, Gender, Parental Smoking, Pocket Money } \\
\text { and year and country dummy variables. } \\
\text { †Inclusive specifications include the following environmental controls: Anti-Smoking } \\
\text { Sentiment, Cigarette Advertising, Anti-Tobacco Media and Youth Access. }\end{array}$} \\
\hline
\end{tabular}

Table 5 Logit models of smoking participation (foreign-brand cigarettes)

\begin{tabular}{lll}
\hline & Baseline $\dagger$ & $\begin{array}{l}\text { Inclusive of environmental } \\
\text { site-specific controls } \dagger \neq\end{array}$ \\
\hline Log price (foreign brand) & $-0.093^{* * *}$ & $-0.061^{* * *}(0.020)$ \\
Anti-smoking sentiment & $(0.023)$ & $-0.090^{* * *}(0.026)$ \\
Cigarette advertising & & $0.112^{* *}(0.046)$ \\
Anti-tobacco media & & $-0.089^{*}(0.051)$ \\
Youth access & & $-0.105^{* * *}(0.028)$ \\
Price elasticity of smoking participation & $-1.617^{* * *}$ & $-1.088^{* * *}$ \\
\hline
\end{tabular}

Coefficients represent the marginal effect of each variable on the probability (rate) of smoking participation.

SEs clustered by survey site.

SEs in parentheses.

${ }^{*} \mathrm{p}<0.1 ;{ }^{* *} \mathrm{p}<0.05 ;{ }^{* *} \mathrm{p}<0.01$.

†All specifications include Age, Age squared, Gender, Parental Smoking, Pocket Money, and year and country dummy variables.

łInclusive specifications include the following environmental controls: Anti-Smoking

Sentiment, Cigarette Advertising, Anti-Tobacco Media and Youth Access.

prevalence rate would be higher by $1.6 \%$ points. Similarly, if anti-tobacco messAges were to reach $100 \%$ of youth as compared with the reported $83 \%$, smoking prevalence would be lower by about $1.5 \%$ points.

We find that youth are more likely to smoke in areas where it is easier for them to purchase cigarettes, as shown by the negative and statistically significant coefficient of Youth Access in tables 4 and 5. Extrapolating from the local-brand cigarette model (table 4), we estimate that if the proportion of youth unable to buy cigarettes increased from the observed mean of $36 \%$ to a hypothetical $100 \%$ (for instance, if bans on selling cigarettes to youth were implemented and fully enforced in all countries), the averAge smoking participation rate would be lower by $6.5 \%$ points.

\section{Cigarette demand among smokers (conditional demand)}

We find that price is a significant predictor of the intensity of smokers' consumption of both local-brand cigarettes (table 6) and foreign-brand cigarettes (table 7). In models inclusive of environmental controls, the price elasticity of conditional demand is -1.37 for local-brand and -1.71 for foreign-brand cigarettes, implying that a $10 \%$ increase in the price of local-brand cigarettes would correspond to a $13.7 \%$ decrease in the averAge number of cigarettes consumed by smokers. Similarly, a $10 \%$ increase in the

Table 6 Generalised linear models of conditional cigarette demand (local-brand cigarettes)

\begin{tabular}{lcc}
\hline & Baseline $\dagger$ & $\begin{array}{l}\text { Inclusive of environmental } \\
\text { site-specific controls } \dagger \neq\end{array}$ \\
\hline Log price (local brand) & $-1.280^{* * *}$ & $-1.365^{* * *}(0.392)$ \\
Anti-smoking sentiment & $(0.241)$ & $-0.110(0.312)$ \\
Cigarette advertising & & $0.861(0.680)$ \\
Anti-tobacco media & & $-1.256^{* *}(0.537)$ \\
Youth access & $0.185(0.339)$
\end{tabular}

Price elasticity of conditional demand $-1.280^{* * *}-1.365^{* * *}$

Coefficients represent the marginal effect of each variable on log cigarettes per month. SEs clustered by survey site.

SEs in parentheses.

${ }^{* *} \mathrm{p}<0.05 ;{ }^{* * *} \mathrm{p}<0.01$

†All specifications include Age, Age Squared, Gender, Parental Smoking, Pocket Money, and year and country dummy variables.

łInclusive specifications include the following environmental controls: Anti-Smoking

Sentiment, Cigarette Advertising, Anti-Tobacco Media and Youth Access. 
Table 7 Generalised linear models of conditional cigarette demand (foreign-brand cigarettes)

\begin{tabular}{lll}
\hline & Baseline $\dagger$ & $\begin{array}{l}\text { Inclusive of environmental } \\
\text { site-specific controls } \dagger \ddagger\end{array}$ \\
\hline Log price (foreign brand) & $-1.547^{* * *}$ & $-1.714^{* * *}(0.511)$ \\
& $(0.327)$ & \\
Anti-smoking sentiment & & $-0.152(0.314)$ \\
Cigarette advertising & $0.989(0.739)$ \\
Anti-tobacco media & $-1.370^{* *}(0.544)$ \\
Youth access & $0.211(0.346)$
\end{tabular}

Price elasticity of conditional demand $-1.547^{* *}-1.714^{* * *}$

\section{What this paper adds}

This paper shows that higher cigarette prices are able to reduce both smoking participation and conditional cigarette demand among youth in our sample of low- and middle-income countries (LMIC). Furthermore, youth are more responsive to price increases in LMIC than high-income countries.

$-1.44 .^{3}$ This is perhaps not surprising, for two reasons. First, the averAge Age in our sample is 14 years, which is generally lower than the Age ranges examined in the literature on US youth smoking. Since younger Age groups have been shown to be more sensitive to prices, ${ }^{3-5} 1718$ it is reasonable to expect that our sample may exhibit higher price responsiveness. Second, income constraints are tighter for individuals from LMIC, which is also likely to result in higher price responsiveness. The argument that people in LMIC are more sensitive to prices than people in HIC is consistent with the findings from a sensitivity analysis we performed in the course of this research. In this sensitivity analysis, we changed the sample of countries so that, in addition to the 17 LMIC in our primary analysis, the sample also included three HIC for which GYTS data were available (Poland, Kuwait and United Arab Emirates). We found that the total price elasticity computed after including the HIC was smaller than the price elasticity of the LMIC sample alone ( -1.8 vs -2.1$)$, confirming that prices can be a more potent tool for controlling consumption in countries with lower incomes.

Although we cannot directly interpret the environmental control variables Cigarette Advertising, Anti-Tobacco Media and Youth Access as indicators for the performance of policies like advertising bans or sales bans to minors, we can, under some assumptions, use them to make an inference about the potential effects of such underlying policies. For instance, we can extrapolate from the Youth Access coefficient in table 4 to estimate that in the hypothetical scenario where youth access bans were universally enforced and no youth were able to purchase cigarettes, the averAge smoking participation rate would drop by $6.5 \%$ points to under $3 \%$. This illustrates the importance of compliance with anti-tobacco policies and highlights the discrepancy in outcomes between actual and desired policy that could arise from inadequate compliance. Indeed, studies from the USA and elsewhere have been inconclusive as far as the impact of youth access policies and their enforcement on youth tobacco use are concerned and highlight the difficulty of enforcing youth access policies. ${ }^{19}$

This study finds that prices are effective policy tools for reducing both smoking participation and conditional cigarette demand among youth in LMIC. While we find evidence that smoking participation rates may also be affected by advertising exposure, anti-tobacco media exposure and ease of purchasing cigarettes, these associations would benefit from further investigation as causal determinants of smoking participation. Among existing smokers, the intensity of cigarette consumption does not appear to be influenced by non-price factors such as advertising exposure and ease of purchasing cigarettes, is mildly influenced by exposure to anti-tobacco media and remains strongly influenced by cigarette prices.

Competing interests None.

Provenance and peer review Not commissioned; externally peer reviewed.
US data. Our estimate of youth price elasticity is higher than the estimates from the US youth data, which range from $-0.7^{78}$ to 


\section{REFERENCES}

1. World Health Organization. Tobacco Fact Sheet. http://www.who.int/ mediacentre/factsheets/fs339/en/index.html (accessed 24 Apr 2011).

2. The Tobacco Atlas. 2006. http://www.whqlibdoc.who.int/publications/2006/ ACS Tobacco Atlas eng.pdf (accessed 24 Apr 2011).

3. Lewit EM, Coate D, Grossman M. The effects of government regulation on teenAge smoking. J Law Econ 1981;24:545-69.

4. Chaloupka FJ, Grossman M. Price, Tobacco Control Policies and Youth Smoking. NBER Working Papers 5740, 1996.

5. Chaloupka FJ, Wechsler H. Price, tobacco control policies and smoking among young adults. J Health Econ 1997;16:359-73.

6. Tauras JA, Markowitz S, Cawley J. "Tobacco control policies and youth smoking: evidence from a new era". In: Lindgren B, Grossman M, eds. Advances in Health Economics and Health Services Research, Vol. 16-Substance Use: Individual Behavior, Social Interactions, Markets and Politics. Oxford, England: Elsevier, 2005.

7. Ross H, Chaloupka FJ. The effect of public policies and prices on youth smoking. South Econ J 2004;70:796-815.

8. Ross H, Chaloupka FJ. The effect of cigarette prices on youth smoking. Health Econ 2003:12:217-30.

9. Decicca P, Kenkel D, Mathios A, et al. Youth smoking, cigarette prices, and antismoking sentiment. Health Econ 2008;17:733-49.
10. Lance PM, Akin JS, Dow WH, et al. Is cigarette smoking in poorer nations highly sensitive to price? Evidence from Russia and China. J Health Econ 2004;23:173-89.

11. Chapman S, Richardson J. Tobacco excise and declining consumption: the case of Papua New Guinea. Am J Public Health 1990;80:537-40.

12. Decicca $\mathbf{P}$, Kenkel D, Mathios A. Putting out the fires: will higher taxes reduce the onset of youth smoking? J Polit Econ 2002;110:144-69.

13. Carpenter C, Cook PJ. Cigarette taxes and youth smoking; new evidence from national, state, and local Youth Risk Behavior Surveys. J Health Econ 2008:27:287-99.

14. Economist Intelligence Unit. Cost of Living Survey. http://www. worldwidecostofliving.com/asp/wcol_WCOLHome.asp (accessed 10 Jun 2010).

15. World Bank. Development Indicators. http://www.data.worldbank.org/indicator (accessed 10 Jun 2010)

16. Tauras JA. Smoke-free air laws, cigarette prices, and adult cigarette demand. Econ Inq 2006;44:333-42.

17. Lewit EM, Coate D. The potential for using excise taxes to reduce smoking. J Health Econ 1982;1:121-45.

18. Harris JE, Chan SW. The continuum-of-addiction: cigarette smoking in relation to price among Americans Aged 15-29. Health Econ 1999;8:81-6.

19. Lantz PM, Jacobson PD, Warner KE, et al. Investing in youth tobacco control: a review of smoking prevention and control strategies. Tob Control 2000;9:47-63.

\section{The Lighter Side}

\section{Forsman}

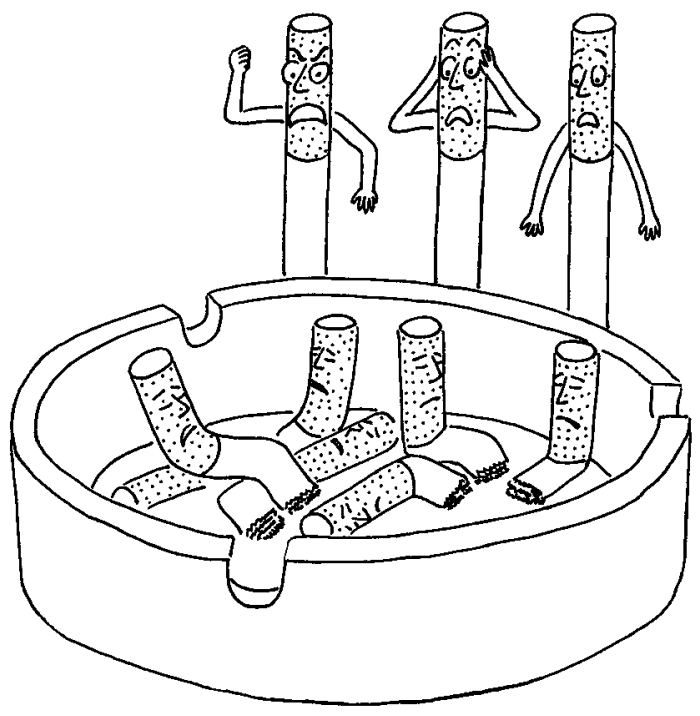

"We will KILL whoever did this!" 


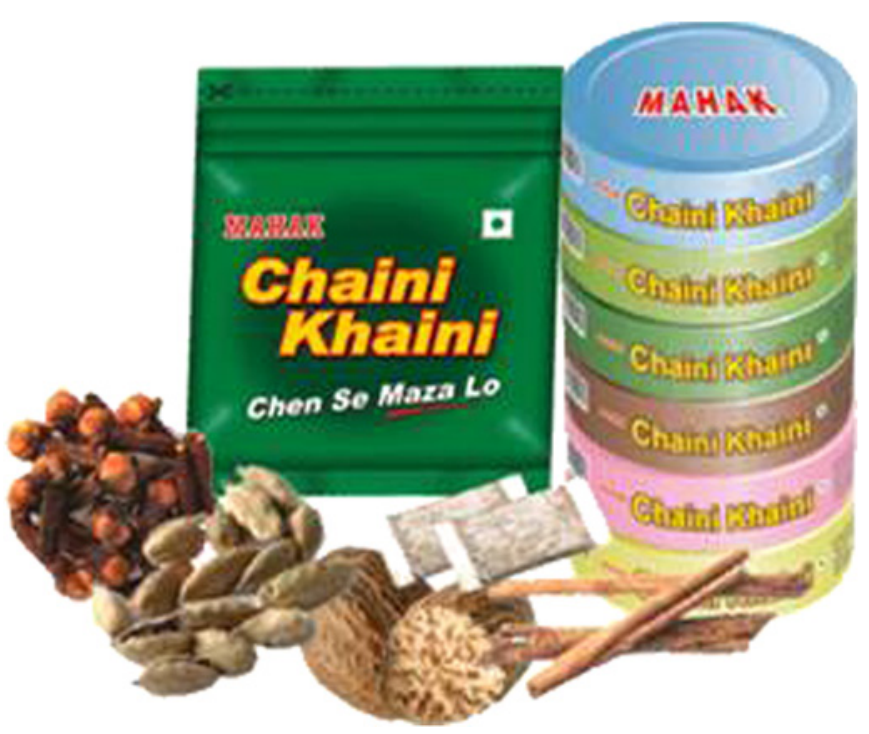

Figure 3 Internet ad for Chaini Khaini illustrating packaging in youthappealing fashion as well as the use of Indian spices and flavouring.

Co-optation of cultural attributes may be a new avenue for multinational tobacco companies to enter largely untapped markets. For India specifically, hybridisation of emerging products, which capitalise on the cultural value of indigenous tobacco, is a potential concern worthy of monitoring. Tobacco control advocates must be vigilant to ensure that these strategies are adequately countered.

Acknowledgements The author would like to thank Pamela Ling, MD, MPH, for her mentorship and encouragement to ensure that this AdWatch was disseminated to tobacco control advocates through publication.

\section{Competing interests None.}

Contributors AM conceived the idea, conducted background research, collected data and drafted the manuscript.

Provenance and peer review Not commissioned; externally peer reviewed.

\section{REFERENCES}

1. Twombly R. Snus use in the U.S.: reducing harm or creating it? J Nat/ Cancer Inst 2010;102:1454-6

2. McNeill A, Sweanor D. Beneficence or maleficence-big tobacco and smokeless products. Addiction 2009;104:167-8.

3. Gupta PC, Ray CS. Smokeless tobacco and health in India and South Asia. Respirology 2003;8:419-31.

4. Mukherjea A, Morgan PA, Snowden LR, et al. Social and cultural influences on tobacco-related health disparities among South Asians in the United States. Tob Control Published Online First: 27 June 2011. doi:10.1136/tc.2010.042309.

5. National Cancer Institute (U.S.). Smokeless Tobacco or Health: An International Perspective. Smoking and Tobacco Control Monograph 2. Bethesda, MD: National Cancer Institute, 1992:413.

6. National Cancer Institute (U.S.), Centers for Disease Control and Prevention (U.S.). Smokeless Tobacco Fact Sheets. Bethesda, MD: National Cancer Institute, 2002:24.

7. Chaini Khaini. http://www.chainikhaini.com (accessed $20 \mathrm{Apr} 2011$ ).

8. Indiamart. http://trade.indiamart.com/details.mp?offer $=1767428888$ laccessed 20 Apr 2011).

9. Savitz DA, Meyer RE, Tanzer JM, et al. Public health implications of smokeless tobacco use as a harm reduction strategy. Am J Public Health 2006;96:1934-9.

\section{Correction}

Kostova D, Ross $\mathrm{H}$, Blecher $\mathrm{E}$, et al. Is youth smoking responsive to cigarette prices? Evidence from low- and middle-income countries (Tob Control 2011;20:419-24). In their literature review, the authors neglected to mention that there are a number of working and discussion papers which examine the relationship between cigarette prices and youth smoking in several lower and middle income countries. These studies use the Global Youth Tobacco Survey and focus on India (Joseph, 2010), Poland (Ross and Prezwonzniak, 2004), Russia (Ross, 2004) and Ukraine (Ross, 2005). The IARC Handbook (currently in print) provides the most up-to-date and comprehensive review of the existing research on the impact of cigarette prices and taxes on smoking behaviour globally. The authors apologise for these omissions.

The list of papers are as follows:

International Agency for Research on Cancer (in press). IARC Handbooks of Cancer Prevention, Tobacco Control, Vol 14: Effectiveness of Tax and Price Policies in Tobacco Control. Lyon, France: International Agency for Research on Cancer.

Joseph RA. The Economics of Youth Tobacco Use in India. Chicago: University of Illinois, 2010

Ross H, Prezwozniak K. Poland 1999 Global Youth Tobacco Survey: Economic Aspects. HNP Discussion Paper Series, Economics of Tobacco Control Paper No. 22. Washington DC: The World Bank, 2004.

Ross H. Russia (Moscow) 1999 Global Youth Tobacco Survey: Economic Aspects. HNP Discussion Paper Series, Economics of Tobacco Control Paper No. 23. Washington DC: The World Bank, 2004.

Ross H. The Ukraine (Kiev) 1999 Global Youth Tobacco Survey: Economic Aspects. HNP Discussion Paper Series, Economics of Tobacco Control Paper No. 20. Washington DC: The World Bank, 2004.

Tobacco Control 2012;21:64. doi:10.1136/tc.2010.038786corr1 